\title{
FIRE FACILITIES AND SITE REQUIREMENTS
}

\author{
David A. Dilling \\ Oak Ridge National Laboratory \\ 855 La Jolla Corona Court \\ La Jolla, California 92037
}

\author{
Tom Brown \\ Princeton Plasma Physics Laboratory \\ Forrestal Campus, Princeton University \\ Princeton, New Jersey 02120
}

\section{ABSTRACT}

This paper describes the buildings and balance of plant systems required to support the Fusion Ignition Research Experiment (FIRE) Project. Facilities and systems are developed on the basis of a "greenfield" site, with no benefit for existing facilities, but also without any constraints on the potential arrangement. Because FIRE will operate deuterium-tritium plasmas for pulse lengths on the order of 20 seconds, FIRE will require a moderate on-site tritium inventory. FIRE buildings and systems must be designed and licensed to comply with regulations for nuclear facilities. They must also include systems to manage tritium and tritiated water, activated dust, and radioactive waste material. Maintenance activities on FIRE will require the use of remote handling systems to remove and transport tokamak parts to hot cell facilities. Major tokamak service connections will be required to feed power to the copper magnet system and deliver plasma-heating energy to ICRF antennae. Competition for access to the tokamak for service connections and repair activities will constrain the overall arrangement and routing of services.

This paper examines the design implications for the fuel supply, vacuum pumping, fuel recovery, cooling, and other balance of plant systems that contribute to the control of radioactive materials. It also examines the design implications for the tokamak test cell, hot cells, structures to house key services, and routing of service connections to the tokamak. Site requirements, a generic site plan, and conceptual building arrangements are provided.

\section{INTRODUCTION}

The goal of the FIRE program is to develop an experimental machine that can access a region of plasma conditions where a significant amount of deuteriumtritium fusion occurs, such that the energy gain is on the order of 10. The FIRE design uses 16 copper plate TF coils, has a major radius of $2.0 \mathrm{~m}$, a minor radius of 0.5 $\mathrm{m}$, and a centerline toroidal field of $10 \mathrm{~T}$. By pre-cooling the coil system to liquid nitrogen temperatures, the FIRE tokamak can achieve operating pulses with flattop conditions for 20 seconds. The tokamak and its major systems are described in other papers and in the FIRE Engineering Report for 2000, which can be found on the PPPL website.

\section{TOKAMAK SERVICES}

The most important tokamak supporting systems to influence the arrangement of buildings and site selection include the following:

Vacuum Pumping and Fueling: Vacuum pumping during a pulse is achieved by cryopumping at $4.2 \mathrm{~K}$. Cryopumps are regenerated back to the main vessel by warming above $25 \mathrm{~K}$ while operating mechanical pumps. The operation of the cryopumps requires a supply of liquid helium at $4.2 \mathrm{~K}$ that can be alternated with a supply of gaseous helium at above $25 \mathrm{~K}$. Cryopumping is the major use of liquid helium. The capacity of the helium refrigerator system is estimated at 120 watts.

Fueling the FIRE tokamak will be accomplished by a combination of gas puffing and pellet injection. Facilities must be provided to store and manage the delivery of hydrogen, deuterium, and tritium to the FIRE fueling systems. Once tritium has been used in FIRE, all exhaust gas from the vacuum system must be recovered and processed. Recovered gasses will be processed to remove impurities and separate isotopes of hydrogen. Separated tritium will be stored on hydride beds. The on-site inventory of tritium will be on the order of $30 \mathrm{~g}$. The lifetime consumption of tritium, assuming 2500 full power D-T shots, will be about $1.5 \mathrm{~kg}$. All fuel reprocessing equipment will be doubly confined, by gloveboxes and by the FIRE buildings.

Plasma Heating: FIRE will utilize about $30 \mathrm{MW}$ of ICRF power to heat the plasma. This energy is supplied by 16 modular power supply and RF signal generation trains. Each train consists of a transformer, power conditioning equipment, and power tetrode module. RF energy at $150 \mathrm{MHz}$ is delivered by co-axial waveguides to four FIRE equatorial ports. Each waveguide is approximately $300 \mathrm{~mm}$ in diameter, and can tolerate bends down to about $1 \mathrm{~m}$ in radius. Each waveguide also has a tuning element that permits the length of the waveguide to be adjusted for phase control.

Magnet Power Supply: The TF magnet system will ramp up for about 19 seconds prior to plasma initiation, and then maintain a constant current during the 20 -second pulse "flattop" condition. The TF system requires a constant 542 MVA during the ramp-up. The power demand at the beginning of flattop is 250 MVA, rising to 333 MVA at the end of the flattop. The energy stored in the TF magnets is about $10.3 \mathrm{GJ}$, and the amount of energy that is absorbed in heating the copper magnets is about 5.8 GJ. About $2.1 \mathrm{GJ}$ is also stored by the CS and PF magnet systems. 
Direct current for the magnets is developed using a total of 28 power conversion trains. Each train consists of a transformer and a phase-controlled thyristor rectifier. Power supply modules are connected in parallel or series, and controlled to provide the desired waveforms. Power is delivered to the tokamak using air-cooled aluminum or copper bus bars.

Cooling Systems: FIRE magnet systems are precooled with liquid nitrogen before each pulse to reduce resistance and increase mechanical strength. During the pulse, the magnets are not cooled, and their temperature increases due to ohmic and nuclear heating. To cool the magnets, liquid nitrogen from storage tanks is pumped through channels in the edges of TF magnet plates, and through holes in the center of other magnet conductors. At the bottom of the tokamak, liquid nitrogen will be collected and recirculated, but nitrogen gas will be vented. About 175,000 liters of $\mathrm{LN}_{2}$ are used to cool the magnets for each pulse.

To actively cool the divertors and other plasma facing components during a pulse, water stored in a cool reservoir is pumped through the divertor cooling channels and into a warm reservoir. Between pulses, the warm water inventory is cooled and returned to the cool reservoir. The FIRE vacuum vessel and first wall are allowed to heat up during a pulse. Between pulses, the heat accumulated by the first wall and vacuum vessel is removed by a continuous small flow of cool water. Both the PFC cooling system and the vacuum vessel cooling system are potentially contaminated, and must be arranged within a confinement boundary.

Remote Handling: Because FIRE will achieve significant power levels with D-T plasmas, it will generate a substantial neutron flux, which will induce radioactivity in the tokamak internals. The combined thickness of the TF magnet and the vacuum vessel is sufficient that these two systems can be augmented with local shielding, and effectively prevent any activation to the tokamak exterior. As a result, the outboard ends of port plugs and many other parts inside the cryostat will remain accessible for hands-on maintenance. However, the internal parts of the tokamak must be maintained using robotic remote handling systems. Access to the port-mounted systems such as ICRF antennae, cryopumps, and most diagnostics will be accomplished by removing the port plug assembly and transporting it to a hot-cell repair facility. However, divertor and first wall modules must be disconnected and extracted using remote manipulators through horizontal port openings. To replace a divertor, FIRE will need 2 or more equatorial port access casks, a remote manipulator system, auxiliary port systems to cut and disconnect piping and supports, and a number of temporary closures and shield plugs. Hot cell facilities to receive failed divertors and shielded storage locations for equatorial ports will also be needed.
The transport of activated divertors must be conducted without any workers present in the test cell.

\section{FIRE FACILITIES}

A set of buildings and site infrastructure has been developed for FIRE, assuming a "greenfield" site. The functional requirements for these buildings are to support, house, and protect the tokamak and activities associated with its construction, operation, and maintenance. In addition, the tokamak building and several others are also assigned to provide appropriate containment of radioactive material, shielding, and protection against design basis hazards such as earthquakes and extreme weather. The tokamak and hot cell systems are located within a single building. The main operating floor of the tokamak and hot cell building is near grade. The structure has a complete lower level, with a clear height of $5 \mathrm{~m}$. The lower space is used to locate the PFC and VV cooling systems, vacuum pumping and fueling systems, LHe auxiliary cold box, and to route bus-bars, ICRF waveguides, and diagnostic signals to the tokamak. When these services connect to the tokamak ports, they generally penetrate the main operating floor in the areas aligned with the magnet centerlines. The spaces aligned with the port centerlines must be kept clear of permanent installations, to allow remote maintenance access to the ports. The main level of the tokamak and hot cell building is divided into three areas. These are the test cell, where the FIRE tokamak is located; the remote handling area, used to store remote handling casks and vehicles when they are not in use; and the hot cells, tool storage rooms, and hot cell operating areas. The tokamak is set in the test cell so that the tokamak centerline is $4.2 \mathrm{~m}$ above the main floor, to allow remote handling cask access to the lower horizontal ports. Movable vertical shields are located at the north and south ends of the test cell. When these shields are raised, it is possible for an overhead bridge crane to service the test cell and remote handling areas. With the southern shield closed and sealed, the building structure forms a continuous boundary around the test cell and remote handling area, providing both shielding and confinement.

There are two hot cells for handling and maintenance of radioactive objects. The smaller cell is configured so that equatorial port assemblies can be placed in openings in a thick wall that duplicate the tokamak port openings. Robot machines can access the plasma-facing end of the port assemblies while the outboard end remains accessible for hands-on maintenance. The larger hot cell is used to receive and manage other irradiated objects, including cryopumps, divertors, and first wall tiles. The hot cell will include facilities to disassemble divertor modules and replace the plasma facing "fingers". Other systems in the hot cell will be used to encapsulate radioactive material 


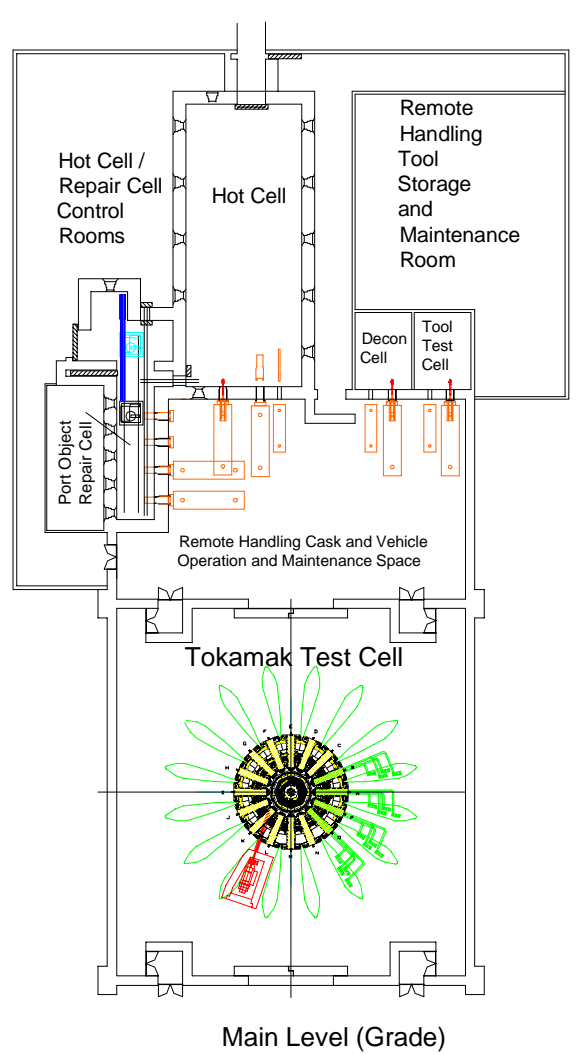

Figure 1 - Tokamak and Hot Cell Building

for off-site disposal.

Other safety-related buildings needed for the FIRE facility include the radioactive systems support building, the liquid radwaste systems building, and the emergency power supply building. All safety related buildings have been estimated assuming that they are predominately reinforced concrete construction. Other buildings, for magnet power conversion, ICRF heating systems, cooling and utility systems are estimated assuming steel-frame on slab construction. The assembly and mockup hall is a two level structure using concrete construction below grade, and steel frame construction above grade.

The conceptual "greenfield" site is arranged to minimize the length of connectors providing services to the tokamak, and to segregate these services as much as possible outside the test cell. Magnet power supplies are located on the West, ICRF on the East, hot cell systems on the North, and assembly staging and diagnostics on the South. The vertical dimension is also required in the test cell to segregate overhead maintenance activities, remote handling, and service routing.

\section{SAFETY AND ENVIRONMENTAL PROTECTION FUNCTIONS}

The building and site arrangements are influenced by some protection functions that they must provide.

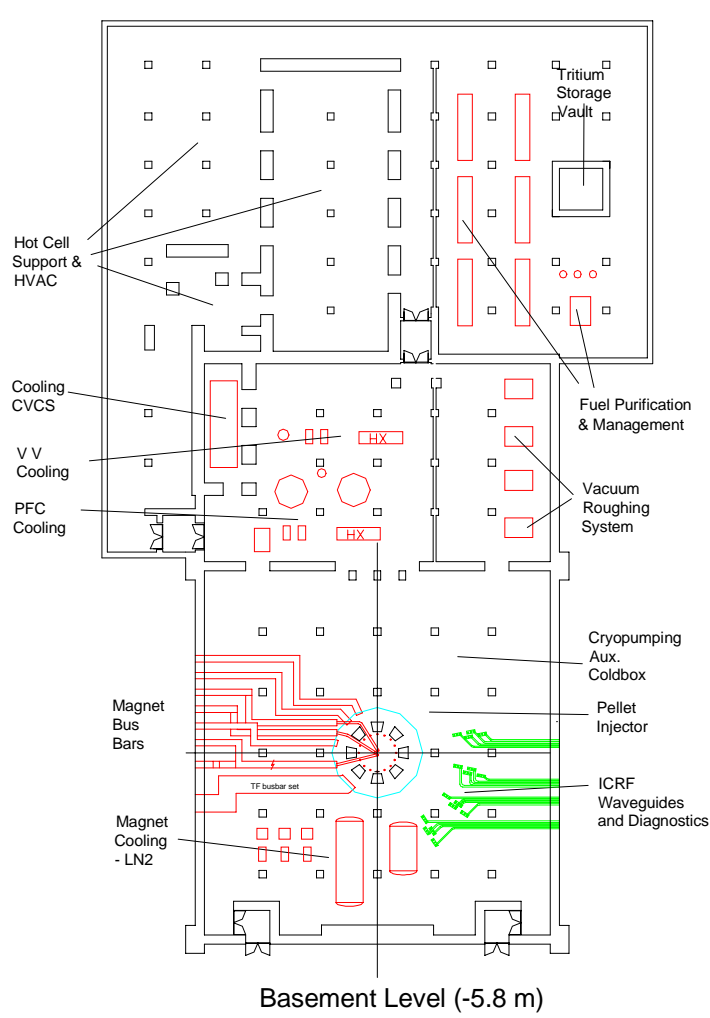

Figure 2 - Tokamak and Hot Cell Basement

Workers must be protected from direct radiation as well as exposure to contaminated and /or toxic materials, and radionuclide sources must be contained to prevent uncontrolled release during accident conditions.

Worker protection is achieved by providing shielding around radiation sources, by designing HVAC systems to control airborne contamination, and by controlling access to the test cell and other areas where exposure is possible. During tokamak operation, the FIRE machine is a significant source of neutron and gamma radiation. Access to the test cell and test cell basement will not be permitted during operation, and the tokamak building walls and roof will be thick enough to shield workers in other parts of the plant. Following D-T operations, the interior of the tokamak and the hot cells are expected to be inaccessible at all times. The tokamak itself provides shielding so that workers can enter the test cell, but the hot cell walls and windows must be thick enough to protect workers from exposed radiation sources inside the cells. The transport of radioactive objects between the tokamak and the hot cells must be accomplished in a way that protects workers. The strategy selected is to isolate the radioactive sources in a movable container, and to rely on distance and the tokamak building to attenuate radiation dose rates. This strategy requires that workers are excluded from the test cell and maintenance area during the transfer, and that the transfer 


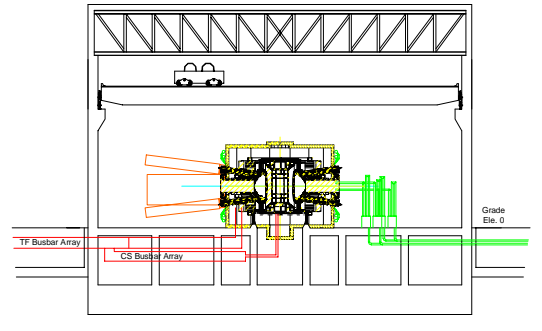

East-West Elevation View

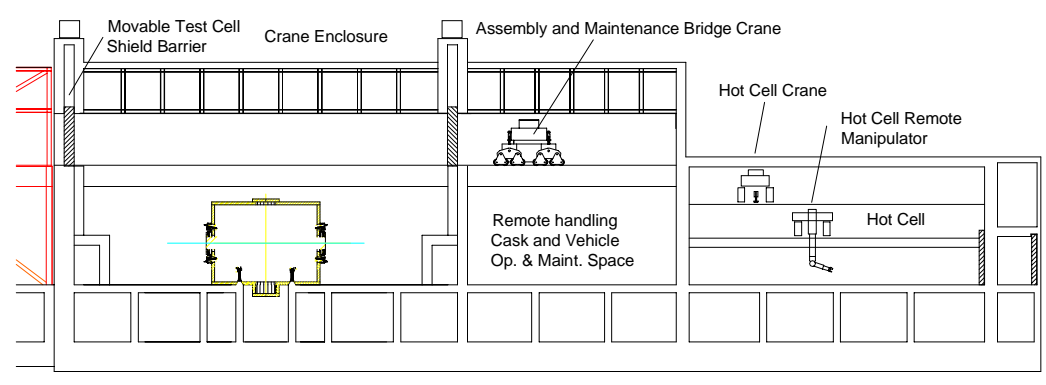

North-South Elevation View

Figure 3 - Tokamak and Hot Cell Building Elevations

machines are capable of remote operation.

Airborne and surface contamination are minimized by the design of the remote handling equipment and HVAC strategy. The remote handling equipment must have double sets of doors so that the tokamak and hot cell spaces are never opened to the test cell. Hot cells form an HVAC space that is filtered, temperature controlled, and de-tritiated by removal of water with a dryer. The test cell, remote maintenance area, and basement under these two areas also form an HVAC space. Airlock doors and negative pressure in these spaces are used to prevent contaminated air from reaching the environment.

The public is protected from an uncontrolled release of radiation by locating all potential release sources inside the confinement boundaries formed by the tokamak building and hot cells. Accident release sources are primarily the mobilizable radionuclides inside the tokamak. Tritium, tungsten dust, beryllium dust, and activated corrosion products in the cooling loops may reach levels that could cause concern. The uncontrolled entry of water into the vacuum vessel, combined with an uncontrolled venting of the vacuum vessel into the tokamak building is a hypothetical, worst case possibility. Analyses to date indicate that the vacuum vessel would not fail under any credible water entry event. However, if the radiological source term were to be released into the tokamak building, it would be confined by the building boundary.

\section{SITING REQUIREMENTS}

To be acceptable, a potential site for FIRE must meet the following criteria:

- Licensability

- Access to electrical power

- Access to industrial infrastructure $\left(\mathrm{LN}_{2}\right.$ etc. $)$

- Access to tritium

- Access to radwaste disposal

- Access to amenities for staff.
It is likely that evolving licensing rules for FIRE will require site boundary public dose limits that are well below limits imposed on commercial nuclear power facilities. A design goal is to assure that there will be no need for offsite evacuation planning or drills. However, with FIRE's low duty cycle and small tritium inventory, these limits should easily be met for all credible accident events. The distance from the release point to the site boundary may not be significantly larger than the space needed to construct and operate FIRE.

The access to electrical power may be a significant constraint on site selection for FIRE. The high power requirement, as much as $800 \mathrm{MW}$, and duty factor less than $0.2 \%$ (about 800 minutes per year) will make FIRE an unattractive customer to most utility systems. From an electric utility point of view, the best sites for FIRE will be locations where the FIRE demand is only about half of the spinning reserve. Access to the grid will require a high voltage transmission line, which can be costly to establish if a right-of-way is not already available. There are several strategies available to FIRE that can help to reduce these difficulties. On-site energy storage is costly, but would reduce demand and increase the duty factor. Utility spinning reserve is highest during periods of lowest consumption - usually at night and weekends. Restricting FIRE operating opportunities to avoid high demand daytime or summertime periods is another alternative means of improving siting opportunities.

FIRE operation will require a large amount of liquid nitrogen for magnet pre-cooling. As with the electrical power, the demand is high, 175,000 liters per shot, but the duty factor is low. The best strategy would be to locate FIRE in an area where a substantial market for liquefied air products exists, and to encourage the development of a nearby commercial plant to fill the needs of both FIRE and the marketplace. The best of circumstances would lead to a plant sufficiently nearby that liquid nitrogen could be supplied to FIRE by pipeline. Alternative strategies would involve significant tankage on the FIRE site, and delivery by truck; or the installation of an industrial scale air liquefaction plant as part of the FIRE facilities. 


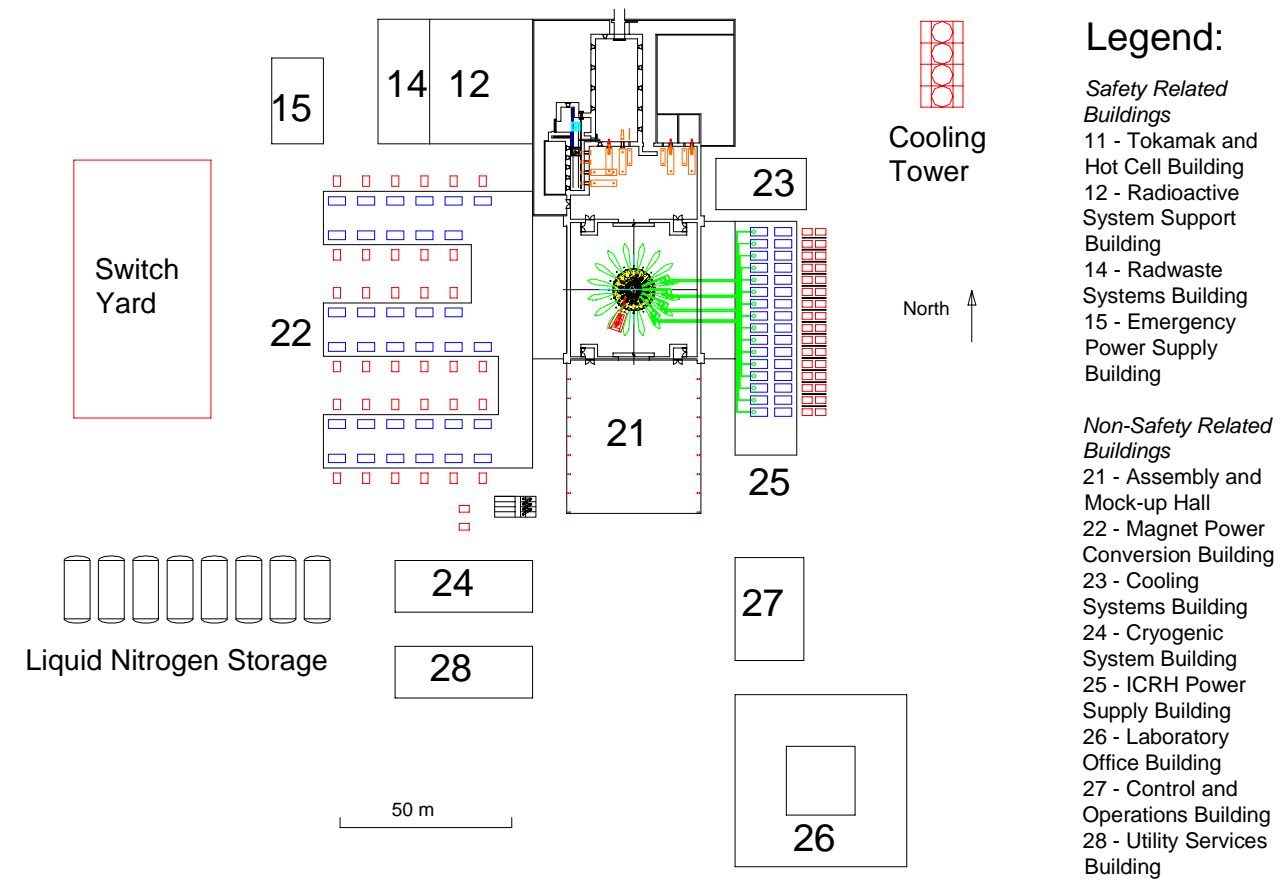

Figure 4 - FIRE “Greenfield” Site Plan

The supply of tritium to FIRE is problematic from a political, not a technical, viewpoint. Tritium is routinely transferred on hydride beds in quantities up to 25 grams. However, permission to transport tritium to and from the FIRE site would require federal, state, and local permits. The FIRE site selection process must acknowledge the potential difficulty associated with this permitting process. The same difficulties are associated with radwaste that will be generated by the FIRE facility. Although quantities are not expected to be large, the eventual disposal of this material could become a siting issue. It is assumed that this waste will be packaged and shipped to an approved waste repository. Permission to ship waste must be obtained from state and local officials, and if across state lines, federal permitting is also required. The proximity of a candidate site for FIRE to a licensed radwaste repository could be an important factor.

The access to amenities such as schooling, housing, an employment market for family members, and cultural attractions is a selection criterion that is very specific to the nature of FIRE and its mission. To successfully pursue its research and development objectives, it is essential that the FIRE program be able to attract and employ a cadre of high level scientific, engineering, and technical craft employees.

\section{CONCLUSIONS}

A number of research vectors are available to pursue the development of controlled fusion. These include projects like ITER and the more moderate Next Step
Options such as FIRE. Any tokamak project that is capable of achieving burning D-T plasma will introduce significant constraints on the design of facilities and the selection of a site. Those constraints are primarily related to the control of radiation exposure. The already significant issues of tokamak design are compounded by licensing, tritium handling, remote handling design, and nuclear safety design issues.

A copper magnet tokamak able to access the burning D-T plasma regime will require substantial support from an outside electrical utility system. Pre-cooling the magnets to liquid nitrogen temperatures improves the electrical performance, but introduces a requirement for substantial industrial infrastructure.

Site selection is seen as an important step towards programmatic approval for FIRE. However, the selection of a site will be highly constrained by balance of plant and facilities features that are required by the project mission.

\section{References:}

1. Dale Meade; "Fusion Ignition Research Experiment"; Comments on Plasma Phys. Controlled Fusion, Comments on Modern Physics, Vol 2(2), pp. 81-97; 2000.

2. R. J. Thome et al; "Engineering Features of the Fusion Ignition Research Experiment (FIRE)"; To be Published in the Proceedings of the $21^{\text {st }}$ Symposium on Fusion Technology (SOFT) August, 2000.

3. FIRE Design Team; "Fusion Ignition Research Experiment (FIRE) Engineering Status Report for Fiscal Year 2000"; Princeton Plasma Physics Laboratory Report No. 81001030_FIREFYRPT_FT.doc. 